Preprint: Joshua M. Pearce. Expanding the Consumer Bill of Rights for material ingredients. Materials Today 21(3), pp. 197-198 (2018). DOI: https://doi.org/10.1016/j.mattod.2018.02.002

\title{
Expanding the Consumer Bill of Rights for Material Ingredients
}

Joshua M. Pearce ${ }^{1,2,3, *}$

1. Department of Materials Science \& Engineering, Michigan Technological University, Houghton, MI USA.

2. Department of Electrical \& Computer Engineering, Michigan Technological University, Houghton, MI USA.

3. Department of Electronics and Nanoengineering, Aalto University, P.O. Box 13500, FI00076 AALTO, Finland

* Correspondence: pearce@mtu.edu ; Tel.: +906-487-1466

\section{Highlights}

> Expanding Consumer Bill of Rights to include materials ingredients:

$>$ creates new business opportunities for superior materials,

$>$ improves consumer safety and enables value-based purchasing,

$>$ fosters advanced industrial as well as distributed recycling.

Keywords: consumer bill of rights; materials; consumer safety; ingredients; consumer products

\section{Introduction}

In President John F. Kennedy's original 1962 speech to the United States Congress he called for the "right to be informed" into what is now called the Consumer Bill of Rights.

Specifically, he pointed out that,

"...if the consumer is unable to choose on an informed basis, then his dollar is wasted, his health and safety may be threatened, and the national interest suffers. On the other hand, increased efforts to make the best possible use of their incomes can contribute more to the well-being of most families than equivalent efforts to raise their incomes. "[1].

At the time, materials science was in its infancy (America's oldest materials science department at Northwestern University was only 7 years old) and by today's standards only crude information technology was available. Thus, the need for consumers to know what materials formed their products to make decisions in their own (and national) best interest was outweighed by the difficulty of providing the information. Fifty-six years later the full list of material ingredients are largely unknown for the vast majority of consumer products, making informed choices impossible everywhere in the world.

With significant evolution in material science and information technology revolution as well as the Internet, the ability to provide materials ingredients for every product is no longer limited by technical feasibility. The materials science community is already well aware of the benefits of materials databases for themselves [2] and have also made efforts to develop consumer product ingredient databases [3]. In addition, the database infrastructure needed to support the concept is already available. For example, the Open Knowledge Foundation's Open Product Data and the Open EAN/GTIN Database both allow users to query barcode numbers online and receive information about products. In addition, every product - which is identified by a globally unique barcode - has its own home page on prod.ly, a social network built on top of the distributed product database ProductLayer. Although providing materials ingredient information to consumers is now technically straight forward, this information is not readily available for the vast majority of products. 
It is time for the Consumer Bill of Rights to be expanded to include digital access to materials ingredient lists for all consumer products. If this change were to take place first in America, the largest consumer market, it would ensure the practice became widespread and provide advantages to all consumers globally. Once companies gathered and shared the information for America, it would be immediately available for all of their other markets. This article will discuss the four core advantages to freely accessible information about the material ingredients for all consumer goods: 1) creating new business opportunities for upselling products manufactured with superior materials, 2) improved consumer safety, 3) enabling purchasing consistent with consumer values, and 4) fostering advanced industrial as well as distributed recycling.

\section{Create new business opportunities}

As there is currently a dearth of information on the materials ingredients within products, firms with products made from superior materials are not easily rewarded for their materials selection. Consumers are generally willing to pay more for products they consider more valuable (e.g. products made from more durable or more environmentally-friendly materials [4]). With free access to materials ingredients, such firms could create a new global class of upselling for products made with superior materials. With a database available, there would also be numerous opportunities for commercial app development to provide data accessibility for specific sets of consumers. For example, smartphone apps already exist for providing consumers with nutritional facts about food. Business opportunities would be created to expand such a range of apps to all aspects of a product (e.g. consumers with skin allergies could purchase an app to help avoid products with allergens). Similarly, such information could be integrated into online sales platforms like Amazon, to further improve their product recommendation algorithms [5].

\section{Improve consumer safety}

Materials ingredients disclosures will improve consumer safety. Many existing products may present a health and safety hazard to specific segments of the population. For example, pregnant women are advised to avoid specific chemicals [6] and apps commercialized by advantage 1, could be used to warn vulnerable consumer populations about avoiding products even at specific times in their lives (e.g. ages of their children). Similarly, consumers would have access to the knowledge to make informed decisions concerning their views of acceptable risk about products with materials that have not been fully tested or have known or suspected negative health or environmental cumulative effects [7]. For example, consumers could begin to make informed decisions about the materials used in furnishing based on their impact on indoor air quality [8]. This would provide an incentive to companies to complete tests to generate more sales for products with good safety data. Again, this knowledge could be made accessible through a service-based business. In addition, if a material used in a product is later found to be toxic, carcinogenic, mutagenic, or teratogenic, materials ingredient information could be useful for the success of recalls.

\section{Enabling consumers to make decisions consistent with their values}

Full access to materials ingredients for all products enable consumers to make purchasing decisions more consistent with their values. For example, a vegan could more easily find alternatives for animal products. There is already a considerable body of literature on ethical consumers, which primarily focuses on the ecologically responsible consumer 
(green consumer) [9]. However, socially conscious consumer choices can promote social causes beyond the environment (e.g. peace or religious freedom) and differ by groups within society (e.g. minorities or migrant workers). Consumers would have the knowledge to choose products based on materials ethically sourced to ensure those that normally pay for the externalities of a technology are protected [10]. California may be moving in this direction already with Environmental Product Declarations, which provides verified, transparent and comparable information about the life-cycle environmental impact of products. Again, companies could be more easily rewarded by ethical consumers preferentially purchasing their products. Consumers would also have the opportunity to purchase products with locally sourced materials going beyond "made in America" in terms of product-miles minimization.

\section{Encourage advanced recycling}

With improved information about the material content of products far more waste could be diverted from incineration or landfilling. For example, in the U.S. there are only seven resin identification codes for polymer recycling, while in China there are 140 codes [11]. There are thousands of polymers and polymer composites used commercially, which could be recycled if they were more easily identified and diverted into recycling centers. Identification would also encourage the development of greener composites and those that could be recycled [12]. This would not only have environmental benefits, but also could accelerate the growth of the more than $\$ 23$ billion global recycling market. In addition, granular materials data for consumer products would enable distributed recycling of household waste into value added products, which in turn would tighten the loop of the circular economy [13] and improve environmental performance [14]. As the economic savings for such recycling are substantial, it would provide everyone that wants it a method to convert their labor into value either for manufacturing their own products or selling their recycled materials to others. Lastly, as the right to repair movement [15] becomes enshrined into law, materials information will enable consumers as well as businesses to provide equivalently functional parts to repair existing products rather than throw them away. Shenzhen provides some insights into this potential benefit as manufacturers there share their bill of materials openly for their electronics-based products. This not only enables advanced recycling, but also accelerates innovation. Sharing is not normally down to full materials compositions and it is cultural not legislated, but their rapid growth from a fishing village to a major center providing $90 \%$ of the world's electronics demonstrates the potential power of this approach.

\section{Conclusions}

Using existing technology and a modest amount of effort the complete material ingredient list could be made available for all consumers to make better informed decisions on their purchases. Such information accessibility would create new business opportunities for upselling products manufactured with superior materials, improve consumer safety, enable consumers to remain consistent with their values, and foster advanced industrial as well as distributed recycling. As the U.S. makes up more than a quarter of the world's market, if the U.S. institutes such a program first, it would be expected to have a catalytic effect and spread the benefits throughout the rest of the world.

\section{Acknowledgements}

The author would like to thank C. Baillie, I. Heikkinen and J. Bow for helpful discussions. This work was supported by Fulbright Finland. 
Preprint: Joshua M. Pearce. Expanding the Consumer Bill of Rights for material ingredients. Materials Today 21(3), pp. 197-198 (2018). DOI: https://doi.org/10.1016/j.mattod.2018.02.002

\section{References:}

[1] Kennedy, John F. (1962) "Special message to the Congress on protecting the consumer interest." Public papers of the presidents of the United States 93, 236. Available online: http://www.presidency.ucsb.edu/ws/?pid=9108

[2] Jain, A., Ong, S. P., Hautier, G., Chen, W., Richards, W. D., Dacek, S., ... \& Persson, K. A. (2013). Commentary: The Materials Project: A materials genome approach to accelerating materials innovation. APL Materials, 1(1), 011002.

[3] Goldsmith, M. R., Grulke, C. M., Brooks, R. D., Transue, T. R., Tan, Y. M., Frame, A., ... \& Isaacs, K. (2014). Development of a consumer product ingredient database for chemical exposure screening and prioritization. Food and Chemical Toxicology, 65, 269-279.

[4] Laroche, M., Bergeron, J., \& Barbaro-Forleo, G. (2001). Targeting consumers who are willing to pay more for environmentally friendly products. Journal of Consumer Marketing, 18(6), 503-520.

[5] Linden, G., Smith, B., \& York, J. (2003). Amazon. com recommendations: Item-to-item collaborative filtering. IEEE Internet Computing, 7(1), 76-80.

[6] Sharpe, R. M., \& Irvine, D. S. (2004). How strong is the evidence of a link between environmental chemicals and adverse effects on human reproductive health?. BMJ: British Medical Journal, 328(7437), 447.

[7] Knudsen, S. H. (2016). Regulating Cumulative Risk. Minnesota Law Review 101:23132396.

[8] Uhde, E., \& Salthammer, T. (2007). Impact of reaction products from building materials and furnishings on indoor air quality - a review of recent advances in indoor chemistry. Atmospheric Environment, 41(15), 3111-3128.

[9] Newholm, T., \& Shaw, D. (2007). Studying the ethical consumer: A review of research. Journal of Consumer Behaviour, 6(5), 253-270.

[10] Franklin, U. (1990). The real world of technology. CBC Enterprises.

[11] Hunt, E. J., Zhang, C., Anzalone, N., \& Pearce, J. M. (2015). Polymer recycling codes for distributed manufacturing with 3-D printers. Resources, Conservation and Recycling, 97, 24-30.

[12] Netravali, A. N., \& Chabba, S. (2003). Composites get greener. Materials today, 6(4), 22-29.

[13] Zhong, S., \& Pearce, J. M. (2018). Tightening the loop on the circular economy:

Coupled distributed recycling and manufacturing with recyclebot and RepRap 3-D printing.

Resources, Conservation and Recycling, 128, 48-58.

[14] Kreiger, M. A., Mulder, M. L., Glover, A. G., \& Pearce, J. M. (2014). Life cycle analysis of distributed recycling of post-consumer high density polyethylene for 3-D printing filament. Journal of Cleaner Production, 70, 90-96.

[15] Wiens, K., \& Gordon-Byrne, G. (2017). The fight to fix. IEEE Spectrum, 54(11), 24-29. 